\title{
Technological parameters of epoxidation of sesame oil with performic acid
}

\author{
Marlena Musik*, Eugeniusz Milchert, Kornelia Malarczyk-Matusiak* \\ West Pomeranian University of Technology Szczecin, Institute of Organic Chemical Technology, Faculty of Chemical \\ Technology and Engineering, Pułaskiego 10, 70-322 Szczecin, Poland \\ "Corresponding author: e-mail: marlena.klos@zut.edu.pl
}

\begin{abstract}
The course of epoxidation of sesame oil (SO) with performic acid formed „in situ” by the reaction of $30 \mathrm{wt} \%$ hydrogen peroxide and formic acid in the presence of sulfuric acid(VI) as a catalyst was studied. The most advantageous of the technological independent parameters of epoxidation are as follows: temperature $80^{\circ} \mathrm{C}, \mathrm{H}_{2} \mathrm{O}_{2} /$ $\mathrm{C}=\mathrm{C}$ 3.5:1, $\mathrm{HCOOH} / \mathrm{C}=\mathrm{C}$ 0.8:1, amount of catalyst as $\mathrm{H}_{2} \mathrm{SO}_{4} /\left(\mathrm{H}_{2} \mathrm{O}_{2}+\mathrm{HCOOH}\right) 1 \mathrm{wt} \%$, stirring speed at least $700 \mathrm{rpm}$, reaction time $6 \mathrm{~h}$. The iodine number (IN), epoxy number (EN), a relative conversion to oxirane (RCO) and oxirane oxygen content (EOe) were determined every hour during the reaction. Under optimal conditions the sesame oil conversion amounted to $90.7 \%$, the selectivity of transformation to epoxidized sesame oil was equal to $93.2 \%, \mathrm{EN}=0.34 \mathrm{~mol} / 100 \mathrm{~g}, \mathrm{IN}=0.04 \mathrm{~mol} / 100 \mathrm{~g}$ oil $(10.2 \mathrm{~g} / 100 \mathrm{~g}$ oil $)$, a relative conversion to oxirane $\mathrm{RCO}=$ $84.6 \%$, and oxirane oxygen content of $\mathrm{EOe}=5.5 \%$.
\end{abstract}

Keywords: sesame oil, epoxidation, performic acid, hydrogen peroxide.

\section{INTRODUCTION}

Epoxidized vegetable oils are used as intermediates for a large number of various applications, for example, as stabilisers and plasticisers in polymers, as additives in lubricants, components in plastics, as the form of polyols in the production of urethane foams ${ }^{1-3}$. The epoxidation can be carried out by different methods. With regard to the ease of polymerization of some oils in the acidic reaction medium, the epoxidation with peracids was carried out in the nonpolar solvents in the presence of homogeneous or heterogeneous catalysts. An acidic catalyst $\left(\mathrm{H}_{2} \mathrm{SO}_{4}\right.$ or cationic ion-exchange resins $)$ is needed to generate the percarboxylic acid by the reaction of carboxylic acid with hydrogen peroxide ${ }^{4-6}$. It results from our unpublished studies that the epoxidation of readily polymerizable oils cannot be carried out by this method. These oils include tung oil and fish oils with a significant content of eleostearic acid. The epoxidation was also carried out with hydrogen peroxide in the presence of phosphotungstate heteropolyacids and the phase-transfer catalysts ${ }^{7,8}$. On a laboratory scale, the epoxidation was performed with hydrogen peroxide or organic hydroperoxides in the presence of titaniumsilicalite catalysts ( $\mathrm{Ti}(\mathrm{IV})-\mathrm{SiO}_{2}$, amorphous $\left.\mathrm{Ti} / \mathrm{SiO}_{2}\right)^{\mathbf{9}, 10}$, transition metal complexes $\left(\mathrm{CH}_{3} \mathrm{ReO}_{3}, \mathrm{CH}_{3} \mathrm{ReO}_{3} /\right.$ $\mathrm{Nb})^{\mathbf{1 1}}$ and by the use of chemoenzymatic methods ${ }^{12,13}$. The only method used in the industrial solutions is the epoxidation by means of pre- or ,in situ” formed percarboxylic acids using hydrogen peroxide and formic, acetic or another short chain acid ${ }^{14-16}$. The largest commercial importance has the epoxidized soybean, rapeseed or canola oil, whereas sunflower, castor, linseed, cotton, corn and other oils are of less importance. The amount of introduced oxirane oxygen is decisive for the epoxidation effectiveness. This amount is dependent on the applied method, used technological parameters and the composition of used vegetable oil.

Sesame oil is of technical importance, and is used in the limited quantities as a food grade oil and the additive to fat products (halva) ${ }^{17}$. A significant production and competitive price in relations to other oils causes the interest in transesterification of sesame oil into biodiesel fuel ${ }^{18}$. With regard to a high content of sterols, tocopherols and other unsaponifiable matter (terpene alcohols, hydrocarbons, other phenolic compounds) especially in a brown variation oil from roasted sesame seeds it can be used as a natural antioxidant for biodiesel and also for food aplications ${ }^{19}$. The unsaponifiable matter can be extracted after saponification of oil at room temperature ${ }^{20}$.

The aim of this study was to determine influence of the technological parameters of sesame oil epoxidation using performic acids, elaboration of the optimal technological parameters (independent variables) and the corresponding them process parameters (results). Particularly important here is high oxirane oxygen value $\left(\mathrm{EO}_{\mathrm{e}}\right)$ or derivatives of this size (selectivity of transformation to oxirane (S), epoxy number (EN), relative conversion to oxirane (RCO). This is due to the wider range of applications especially in the production of polyols and polyurethanes. Moreover, it allows to explain the issue of safe conduct of the process.

A high acidity of formic acid will cause the faster rate of epoxidation in a comparison with the process carried out using acetic acid. In the case of insufficient removal of the reaction heat this can result in rapid growth of temperature and uncontrolled reaction route ${ }^{21}$.

The epoxidation of sesame oil with performic acid has not yet been reported. We have performed the selective epoxidation of sesame oil with peracetic acid ${ }^{22}$. This enables a comparison of the results of epoxidation by means of both peracids. In the epoxidation process of oils with percarboxylic acids as well as in other epoxidation methods, it is essential to establish such technological parameters so that the oxirane rings opening will not proceed. The oxirane ring opening proceeds under the influence of water, carboxylic and percarboxylic acid in the presence of mineral acids (also the cation exchange resin). An acidic reaction medium causes also the isomerization of the epoxy groups to the carbonyl groups. These reactions can be eliminated or significantly limited by optimization of the technological parameters. 


\section{EXPERIMENTAL}

Materials. Sesame oil was obtained from Biooil Laboratory, Poland. Determined amounts of acids in oil are presented in Table $1^{23}$. The iodine number was IN $=110.3 \mathrm{~g} / 100 \mathrm{~g}$ of oil, acid value $0.2 \mathrm{mg} \mathrm{KOH} / \mathrm{g}$ oil, saponification value $191 \mathrm{mg} \mathrm{KOH} / \mathrm{g}$ oil. Formic acid, $85 \mathrm{wt} \%$ (analytical reagent grade), $30 \mathrm{wt} \%$ aqueous hydrogen peroxide and sulfuric acid(VI) $95 \mathrm{wt} \%$ were purchased from POCh Poland.

Epoxidation procedure. The required amount of sesame oil $(100 \mathrm{~g})$ was placed in a glass reactor of $250 \mathrm{~mL}$ capacity, equipped with propeller stirrer, with control of rotation speed $(2.1 \mathrm{~cm}$ diameter, four bladed turbine type glass stirrer), reflux condenser, dropping funnel and thermometer. The reactor was located in a thermostated oil bath, whose temperature was maintained within $\pm 1^{\circ} \mathrm{C}$. During stirring, the reactor was charged with a known amount of formic acid and the catalyst $\left(\mathrm{H}_{2} \mathrm{SO}_{4}\right)$. A 30 wt $\%$ aqueous hydrogen peroxide was added dropwise to maintain the desired reaction temperature. The time of dropwise addition of $\mathrm{H}_{2} \mathrm{O}_{2}$ solution was 25-36 min. In addition, the epoxidation with one-time introduction of hydrogen peroxide was performed. The most advantageous technological parameters were used in these experiments. After the complete addition of hydrogen peroxide, the reaction was further continued over a required period of time. At the beginning the aqueous phase constituted $16-37 \%$ of the reaction mixture depending on the molar ratio of reactants and other parameters. It decreased during epoxidation due to reactive extraction of hydrogen peroxide. The moment of hydrogen peroxide addition was considered as the zero time. The course of the process was followed by collecting the samples and performing analyzes at regular intervals. The influence of the following technological parameters: temperature, hydrogen peroxide and formic acid to sesame oil molar ratio, amount of sulfuric acid introduced, effect of stirring speed and reaction time were studied. After a specified time of process duration, the samples were cooled to the ambient temperature, then a separated organic layer was neutralized by a $5 \mathrm{wt} \%$ solution of sodium carbonate to obtain the $\mathrm{pH}=7$. The organic layer was rinsed with water and dried over anhydrous $\mathrm{MgSO}_{4}$.

Analytical techniques. The composition of fatty acids in used sesame oil was determined by a gas chromatography. The analyses were carried out using Thermo Scientific Focus GC apparatus with flame ionization detector. A capillary column TR-WAX $30 \mathrm{~m} \times 0.26$ $\mathrm{mm} \times 0.5 \mu \mathrm{m}$ worked at temperature $220^{\circ} \mathrm{C}$, detector temperature was $260^{\circ} \mathrm{C}$. The carrier gas was hel -144 $\mathrm{mL} / \mathrm{min}$. A sample was injected in place of feeder with a partition (split 1:90).

The course of the process was controlled every hour by the determination of the iodine number (IN) ${ }^{24}$ and epoxy number $(\mathrm{EN})^{25}$. Based on the conversion of sesame oil $\left(\mathrm{C}_{\mathrm{SO}}\right)$, the selectivity of transformation to the epoxidized oil ( $\mathrm{S}$ ), a relative conversion to oxirane $(\mathrm{RCO})$ and oxirane oxygen content $\left(\mathrm{EO}_{\mathrm{e}}\right)$ were calculated. The conversion was calculated according to the following equation:

$C_{S O}=\frac{I N_{0}-I N}{I N_{0}} * 100 \%$ where $\mathrm{IN}_{0}$ - is the iodine number of sesame oil before epoxidation (110.3 g/100 g); IN - is the iodine number of sesame oil at a given moment of reaction time.

The selectivity was calculated from equation:

$S=\left(\frac{E O_{e}}{E O_{t}} * \frac{I N_{0}}{I N_{0}-I N}\right) * 100 \%$

where $\mathrm{EO}_{\mathrm{e}}(\%)$ - is the experimentally determined content of oxirane oxygen in $100 \mathrm{~g}$ of oil ${ }^{26}$ :

$E O_{e}=\frac{V * N * 1.60}{w}=E N * 16$

where $\mathrm{V}$ - the volume of standard hydrogen bromide solution in $\mathrm{mL}$,

$\mathrm{N}$ - molarity of the hydrogen bromide solution in $\mathrm{mol} / \mathrm{L}$,

$\mathrm{w}-$ the weight of the sample in $\mathrm{g}$.

$\mathrm{EO}_{\mathrm{t}}(\%)$ - the theoretical maximum oxirane oxygen in $100 \mathrm{~g}$ of oil was calculated as follows ${ }^{5,27,28}$ :

$\left.\left.E O_{t}=\left\{\left(\frac{I N_{0}}{2 A_{I}}\right) /\left[100+\left(\frac{I N_{0}}{2 A_{I}}\right) * A_{0} \mid\right]\right\}\right)\right\} A_{0} * 100$

where $A_{I}=126.9$ is the atomic weight of iodine $(\mathrm{g} / \mathrm{mol})$. For $\mathrm{IN}_{0}=110.3 \mathrm{~g} / 100 \mathrm{~g}$ of oil $(0.43 \mathrm{~mol} / 100 \mathrm{~g}$ of oil), $\mathrm{EO}_{\mathrm{t}}$ is equal to $6.5 \%$.

A relative conversion to oxirane was calculated as follows :

$R C O=E O_{e} / E O_{t} * 100 \%$.

Moreover, the content of glycols was determined after completing each experiment, using a method based on the oxidation with benzyltrimethylammonium perioda$t^{26}$. Some experimental runs were repeated in order to determine the percentage variation between the experimental results. The maximum variation was found to be from 1.3 to $5.0 \%$.

\section{RESULTS AND DISCUSSION}

The composition of sesame oil and other values were presented in Table 1:

The influence of the technological parameters on the sesame oil epoxidation was studied in the temperature range $30-90^{\circ} \mathrm{C}$, at hydrogen peroxide to ethylenic unsaturation molar ratio $\mathrm{H}_{2} \mathrm{O}_{2} / \mathrm{C}=\mathrm{C}=0.8: 1$ to $5.0: 1$, and formic acid to ethylenic unsaturation molar ratio $\mathrm{HCOOH} / \mathrm{C}=\mathrm{C}=0.2: 1$ to $1.0: 1$, stirring speed $400-1800$ rpm, over the time of 1-12 $\mathrm{h}$ or 1-7 $\mathrm{h}$. The concentration of sulphuric acid(VI) as a catalyst, measured in relation to the epoxidizing agent was increased within the range $\left(\mathrm{H}_{2} \mathrm{SO}_{4}\right) /\left(\mathrm{H}_{2} \mathrm{O}_{2}+\mathrm{HCOOH}\right)=0.5$ to $4.0 \mathrm{wt} \%$. A selection of technological parameters was performed after completing the preliminary trials of sesame oil epoxidation and based on the parameters of epoxidation of other oils (soybean, rapeseed, linseed).

Effect of temperature. The effect of temperature was studied by determining the iodine and epoxy numbers at $30,45,60,75$ and $90^{\circ} \mathrm{C}$. The following parameters were established: the molar ratio of $\mathrm{H}_{2} \mathrm{O}_{2} / \mathrm{C}=\mathrm{C}=1.5: 1$, $\mathrm{HCOOH} / \mathrm{C}=\mathrm{C}=0.5: 1$, stirring speed $700 \mathrm{rpm}$, reaction time 1-12 $\mathrm{h}$. The amount of catalyst in relation to the epoxidizing agent was equal to $\left(\mathrm{H}_{2} \mathrm{SO}_{4}\right) /\left(\mathrm{H}_{2} \mathrm{O}_{2}+\mathrm{HCO}\right.$ $\mathrm{OH})=2.0 \mathrm{wt} \%$. On the basis of experimental results it was found that the highest epoxy number $(\mathrm{EN}=0.178$ 
Table 1. Molar mass of sesame oil and fatty acids fractions

\begin{tabular}{|c|c|c|c|c|}
\hline$A^{a}: B^{b}$ & Fatty acid & $\begin{array}{c}\mathrm{g} \\
{[\mathrm{wt} \%]}\end{array}$ & $\begin{array}{c}\mathrm{M}_{\mathrm{GT}} \\
{[\mathrm{g} / \mathrm{mol}]}\end{array}$ & $\begin{array}{c}\mathrm{M}_{\mathrm{x}} \\
{[\mathrm{g} / \mathrm{mol}]}\end{array}$ \\
\hline $16: 0$ & $\mathrm{CH}_{3}\left(\mathrm{CH}_{2}\right)_{14} \mathrm{COOH}$ & 10.6 & 806 & 85.4 \\
\hline 18:0 & $\mathrm{CH}_{3}\left(\mathrm{CH}_{2}\right)_{16} \mathrm{COOH}$ & 5.7 & 890 & 50.7 \\
\hline $18: 1$ & $\mathrm{CH}_{3}\left(\mathrm{CH}_{2}\right)_{7} \mathrm{CH}=\mathrm{CH}\left(\mathrm{CH}_{2}\right)_{7} \mathrm{COOH}$ & 45.1 & 884 & 398.1 \\
\hline $18: 2$ & $\mathrm{CH}_{3}\left(\mathrm{CH}_{2}\right)_{3}\left(\mathrm{CH} \mathrm{H}_{2} \mathrm{CH}=\mathrm{CH}\right)_{2}\left(\mathrm{CH}_{2}\right)_{7} \mathrm{COOH}$ & 32.9 & 878 & 88.6 \\
\hline $18: 3$ & linolenic $(9 \mathrm{cis}, 12 \mathrm{cis}, 15 \mathrm{cis}) \quad \mathrm{CH}_{3}\left(\mathrm{CH}_{2} \mathrm{CH}=\mathrm{CH}\right)_{3}\left(\mathrm{CH}_{2}\right)_{7} \mathrm{COOH}$ & 4.3 & 872 & 37.5 \\
\hline $20: 4$ & arachidonic $(5-, 8-, 11-, 14-\mathrm{cis}) \mathrm{CH}_{3}\left(\mathrm{CH}_{2}\right)_{4}\left(\mathrm{CH}=\mathrm{CHCH}_{2}\right)_{4}\left(\mathrm{CH}_{2}\right)_{2} \mathrm{COOH}$ & 0.6 & 974 & 6.1 \\
\hline $20: 1$ & gadoleic (9-cis) $\quad \mathrm{CH}_{3}\left(\mathrm{CH}_{2}\right)_{9}(\mathrm{CH}=\mathrm{CH})\left(\mathrm{CH}_{2}\right)_{7} \mathrm{COOH}$ & 0.4 & 968 & 4.3 \\
\hline $22: 1$ & erucic (13-cis) $\quad \mathrm{CH}_{3}\left(\mathrm{CH}_{2}\right)_{7} \mathrm{CH}=\mathrm{CH}\left(\mathrm{CH}_{2}\right)_{11} \mathrm{COOH}$ & 0.4 & 1052 & 4.2 \\
\hline
\end{tabular}

$\mathrm{g}$ - the content of given fatty acid in sesame oil, $\mathrm{M}_{\mathrm{GT}}$ - molar mass of triglyceride in the case of the presence of selected fatty acid, $\mathrm{M}_{\mathrm{x}}$ - a mass fraction of particular carboxylic acids in triglycerides.

mol/100g) was achieved at temperature of $90^{\circ} \mathrm{C}$, after the time 3 h (Fig. 1).

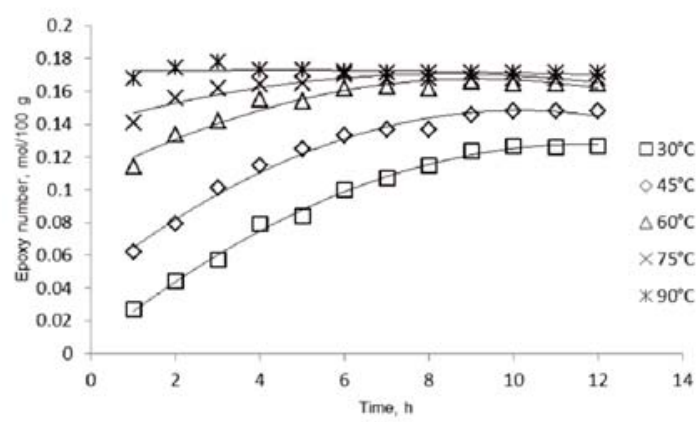

Figure 1. Effect of temperature on the epoxy number (EN). Conditions: formic acid to ethylenic unsaturation molar ratio $\mathrm{HCOOH} / \mathrm{C}=\mathrm{C}=0.5: 1$, hydrogen peroxide to ethylenic unsaturation molar ratio $\mathrm{H}_{2} \mathrm{O}_{2} / \mathrm{C}=\mathrm{C}=$ 1.5:1, amount of catalyst $\left(\mathrm{H}_{2} \mathrm{SO}_{4}\right) /\left(\mathrm{H}_{2} \mathrm{O}_{2}+\mathrm{HCOOH}\right)$ $=2 \mathrm{wt} \%$, stirring speed $700 \mathrm{rpm}$

A decrease of the epoxy numbers to a constant value $\mathrm{EN}=0.170 \pm 0.03 \mathrm{~mol} / 100 \mathrm{~g}$ takes place after this time. This means a slight increase in the rate of the oxirane rings opening reaction, mainly due to the hydration. Slightly lower values of EN occur at a temperature of $75^{\circ} \mathrm{C}$ over a period of $6-12 \mathrm{~h}$, whereas at $60^{\circ} \mathrm{C}$ after the time from 9 to $12 \mathrm{~h}$. The epoxy number at temperatures $45^{\circ} \mathrm{C}$ and $30^{\circ} \mathrm{C}$ was significantly lower even after longer reaction times ( 9 and $10 \mathrm{~h}$, respectively). A larger decrease of the iodine number (IN) during a prolongation of the reaction time was observed at lower temperatures (30, 45 and $60^{\circ} \mathrm{C}$ ). The lowest and slightly different values of the iodine number as a function of the reaction time occurred at a temperature of $90^{\circ} \mathrm{C}(0.203 \mathrm{~mol} / 100 \mathrm{~g}$ after time of $6 \mathrm{~h}$ or longer). However these values were slightly higher at a temperature of $75^{\circ} \mathrm{C}$ (Fig. 2).

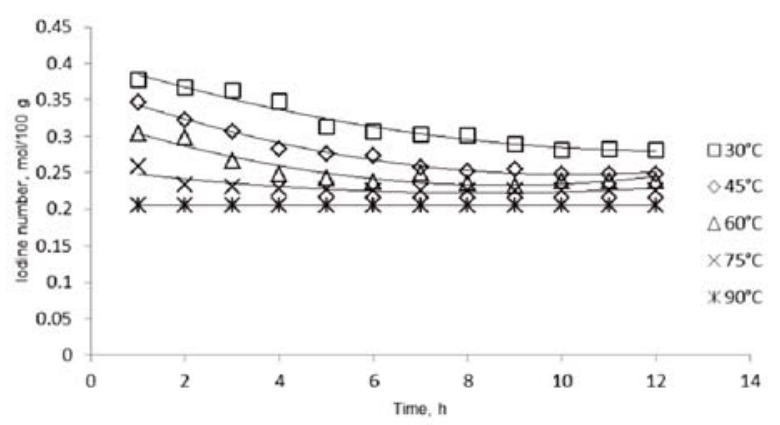

Figure 2. Effect of temperature on the iodine number (IN). Technological parameters as in Fig. 1
The sesame oil conversion at $90^{\circ} \mathrm{C}$ after the time of $3 \mathrm{~h}$ amounted to $\mathrm{C}_{\mathrm{SO}}=53.7 \%$, at the selectivity of transformation to the oxirane ring $\mathrm{S}=81.6 \%$. After the same time at a temperature of $75^{\circ} \mathrm{C}$ these magnitudes amounted to $\mathrm{C}_{\mathrm{SO}}=46.5 \%$ and $\mathrm{S}=85.7 \%$ respectively. A higher selectivity and the occupational safety issues appeal to operate the process at lower temperature. This becomes particularly important after increasing the scale of the process. Then occurs a less favourable ratio of the cooling surface to a volume of the reaction mass and the amount of cooling medium is increased.

Slight differences among the magnitudes describing the epoxidation (process parameters: IN, EN, EO, $\mathrm{C}_{\mathrm{SO}}, \mathrm{S}, \mathrm{RCO}$ ) at temperatures of 75 and $90^{\circ} \mathrm{C}$ cause that a temperature of $80^{\circ} \mathrm{C}$ was recognized as the most advantageous in this series of studies. The reaction time of $6 \mathrm{~h}$ is required at temperature of $80^{\circ} \mathrm{C}$, whereas the epoxy number does not undergo a change over a period from 6 to $12 \mathrm{~h}$, and the iodine number slightly decreases over a period from 6 to $10 \mathrm{~h}$. After a further prolongation of the reaction time, the iodine number maintains a constant value. The remaining results: $\mathrm{EN}, \mathrm{EO}_{\mathrm{e}}, \mathrm{C}_{\mathrm{SO}}$, $\mathrm{S}$, RCO undergo only slight changes.

Influence of amount of catalyst. $\left(\mathrm{H}_{2} \mathrm{SO}_{4}\right) /\left(\mathrm{H}_{2} \mathrm{O}_{2}+\mathrm{HCO}-\right.$ $\mathrm{OH})$. In the studies of this series, the mass concentration of sulphuric acid(VI) in relation to the epoxidation agent $\left(\mathrm{H}_{2} \mathrm{SO}_{4}\right) /\left(\mathrm{H}_{2} \mathrm{O}_{2}+\mathrm{HCOOH}\right)$ was increased from $0.5 \mathrm{wt} \%$ to $4.0 \mathrm{wt} \%$. The remaining technological parameters were as follows: temperature $80^{\circ} \mathrm{C}$, molar ratio $\mathrm{H}_{2} \mathrm{O}_{2}$ / $\mathrm{C}=\mathrm{C}=1.5: 1, \mathrm{HCOOH} / \mathrm{C}=\mathrm{C}=0.5: 1$, stirring speed $700 \mathrm{rpm}$. The values of the process parameters (EN, IN, RCO, $\mathrm{EO}_{\mathrm{e}}, \mathrm{C}_{\mathrm{SO}}, \mathrm{S}$ ) were measured every $1 \mathrm{~h}$ over the time period of $1-10 \mathrm{~h}$. Under these conditions the highest degree of conversion of the unsaturated bonds to the epoxy groups $(\mathrm{EN})$ was found at the catalyst concentration of $1.0 \mathrm{wt} \%$ after the time of $6 \mathrm{~h}$ (Fig. 3) and this conversion decreases along with a prolongation of the reaction time over a period from $6 \mathrm{~h}$ to $10 \mathrm{~h}$.

A very similar course of changes of the epoxy numbers (EN) occurred at the catalyst concentration of $1.5 \mathrm{wt} \%$ in the same time period. A decrease of the epoxy numbers is caused by the side reactions due to the oxirane rings opening, mostly in the reaction with water and formic acid resulting in the formation of glycols and hydroxyl formates. This is most intensive at the catalyst concentration $\mathrm{H}_{2} \mathrm{SO}_{4} /\left(\mathrm{H}_{2} \mathrm{O}_{2}+\mathrm{HCOOH}\right)=4.0 \mathrm{wt} \%$. At the catalyst concentration of $4.0 \mathrm{wt} \%$ the oxirane ring is opened quickly at the beginning of the reaction. Therefore, the nature of the course of the curve changes. The epoxy number decreases during a prolongation of the 


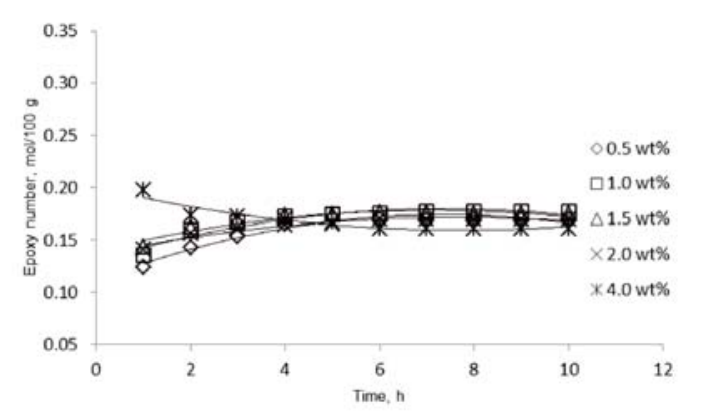

Figure 3. Effect of amount of catalyst $\left(\mathrm{H}_{2} \mathrm{SO}_{4}\right) /\left(\mathrm{H}_{2} \mathrm{O}_{2}+\right.$ $\mathrm{HCOOH})$ on the epoxy number $(\mathrm{EN})$. Conditions: temperature $80^{\circ} \mathrm{C}$, hydrogen peroxide to ethylenic unsaturation molar ratio $\mathrm{H}_{2} \mathrm{O}_{2} / \mathrm{C}=\mathrm{C}=1.5: 1$, formic acid to ethylenic unsaturation molar ratio $\mathrm{HCOOH} /$ $\mathrm{C}=\mathrm{C}=0.5: 1$, stirring speed $700 \mathrm{rpm}$

reaction time from $1 \mathrm{~h}$ to $6 \mathrm{~h}$, and after that time their constant, lowest values are established. To these values correspond the lowest iodine numbers. Moreover at any, catalyst concentration selected from studied range after the time of $6 \mathrm{~h}$, the constant lowest iodine numbers (IN) were obtained. To these values correspond the lowest epoxy numbers at a given catalyst concentration or these numbers undergo decrease along with a decrease of oxirane oxygen content $\left(\mathrm{EO}_{\mathrm{e}}\right)$. An enhancement of the catalyst amount was aimed to increase the rate of performic acid formation. Due to this, an acceleration of the slowest stage - the formation of performic acid, is possible. However, at a high concentration of the catalyst $-4.0 \mathrm{wt} \%$ was found a significantly larger growth of the rate of oxirane ring destruction. As a results of this destruction, the fractions of glycols $(0.06 \mathrm{~mol} / 100 \mathrm{~g})$, and hydroxy formates were increased. Similar relationships were observed for the influence of sulphuric acid on the rate enhancement of epoxidation of soybean and mahua oil, as reported by Petrović and Goud ${ }^{3,30}$.

Influence of formic acid to ethylenic unsaturation molar ratio $(\mathrm{HCOOH} / \mathrm{C}=\mathrm{C})$. The effect of this molar ratio was studied at $\mathrm{HCOOH} / \mathrm{C}=\mathrm{C}=0.2: 1,0.5: 1,0.8: 1$, 1.0:1. The $\mathrm{H}_{2} \mathrm{O}_{2} / \mathrm{C}=\mathrm{C}$ molar ratio was maintained at 1.5:1. Other values of the technological parameters were maintained at a level previously provided (temperature $80^{\circ} \mathrm{C}$, amount of catalyst $1.0 \mathrm{wt} \%$, stirring speed 700 $\mathrm{rpm})$. Fig. 4 shows that the highest values of $\mathrm{EN}=$ $0.180 \pm 0.002 \mathrm{~mol} / 100 \mathrm{~g}$ are obtained at the molar ratio $\mathrm{HCOOH} / \mathrm{C}=\mathrm{C}=0.8: 1$ and $1.0: 1$, when the process is carried out for at least $5 \mathrm{~h}$.

A prolongation of time to $7 \mathrm{~h}$ does not decrease the EN values. To these values of EN correspond the highest values of RCO, $\mathrm{EO}_{\mathrm{e}}, \mathrm{C}_{\mathrm{SO}}, \mathrm{S}$ and the lowest IN. Hence, the most appropriate molar ratio of $\mathrm{HCOOH} /$ $\mathrm{C}=\mathrm{C}$ amounts $0.8: 1$ at the reaction time of $5 \mathrm{~h}$. The lower molar ratios of $\mathrm{HCOOH} / \mathrm{C}=\mathrm{C}=0.2$ and 0.5 over the examined time period lead to smaller values of $\mathrm{EN}$, $\mathrm{RCO}$ and $\mathrm{EO}_{\mathrm{e}}$. Diminishing iodine numbers correspond to these values. After $5 \mathrm{~h}$ each process parameters (EN, $\mathrm{IN}, \mathrm{RCO}, \mathrm{EO}_{\mathrm{e}}$ ) maintains a constant value, characteristic for a given molar ratio of $\mathrm{HCOOH} / \mathrm{C}=\mathrm{C}$. A significant decrease of the iodine numbers at the molar ratios of $\mathrm{HCOOH} / \mathrm{C}=\mathrm{C}=0.2: 1$ and $0.5: 1$, over a time period from 1 to $5 \mathrm{~h}$ accompanies the increase in the epoxy

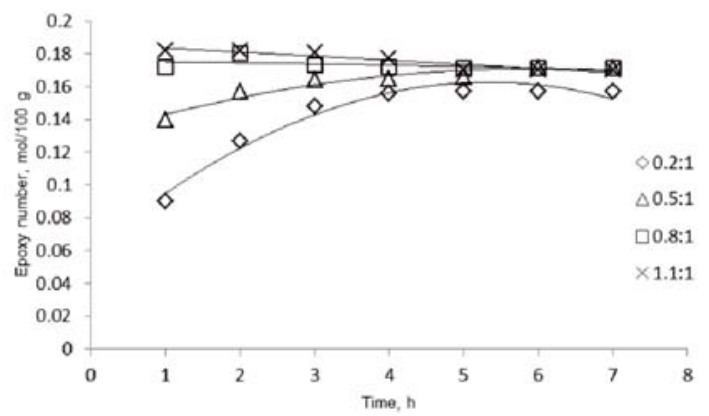

Figure 4. Effect of formic acid to ethylenic unsaturation molar ratio $(\mathrm{HCOOH} / \mathrm{C}=\mathrm{C})$ on the epoxy number $(\mathrm{EN})$. Conditions: temperature $80^{\circ} \mathrm{C}$, hydrogen peroxide to ethylenic unsaturation molar ratio $\mathrm{H}_{2} \mathrm{O}_{2} / \mathrm{C}=\mathrm{C}=$ 1.5:1, amount of catalyst $\left(\mathrm{H}_{2} \mathrm{SO}_{4}\right) /\left(\mathrm{H}_{2} \mathrm{O}_{2}+\mathrm{HCOOH}\right)$ $=1 \mathrm{wt} \%$, stirring speed $700 \mathrm{rpm}$

numbers. This indicates that a significant amount of the unsaturated bonds overreact to the oxirane groups. After the time of $6 \mathrm{~h}$ and longer, the values of EN, IN and the remaining process parameters are constant. Over the studied range of changes of the molar ratio $\mathrm{HCOOH} /$ $\mathrm{C}=\mathrm{C}$ occur relatively small changes in the glycols concentration. The determinations of glycol concentrations indicate the value of $0.02-0.05 \mathrm{~mol} / 100 \mathrm{~g}$. A growth of the hydrolysis rate of the oxirane ring to glycols due to the increase in the molar ratio of $\mathrm{HCOOH} / \mathrm{C}=\mathrm{C}$ does not occur.

Influence of hydrogen peroxide to ethylenic unsaturation molar ratio $\left(\mathrm{H}_{2} \mathrm{O}_{2} / \mathrm{C}=\mathrm{C}\right)$. The studies of the influence of hydrogen peroxide to ethylenic unsaturation molar ratio in sesame oil on the course of epoxidation were carried out at the following ratios: $\mathrm{H}_{2} \mathrm{O}_{2} / \mathrm{C}=\mathrm{C}=5.0: 1$, 3.5:1, 2.5:1, 2.0:1, 1.5:1, 1.1:1 and 0.8:1. The experiments of this series were carried out at a temperature of $80^{\circ} \mathrm{C}$, at the molar ratio $\mathrm{HCOOH} / \mathrm{C}=\mathrm{C}=0.8: 1$, the catalyst concentration $\mathrm{H}_{2} \mathrm{SO}_{4} /\left(\mathrm{H}_{2} \mathrm{O}_{2}+\mathrm{HCOOH}\right)=1.0 \mathrm{wt} \%$ and stirring speed $700 \mathrm{rpm}$. The process parameters (results) were calculated every hour over a period from 1 to $7 \mathrm{~h}$. The results in the form of the courses of changes of a relative conversion to oxirane (RCO) as a function of the reaction time are presented in Fig. 5 .

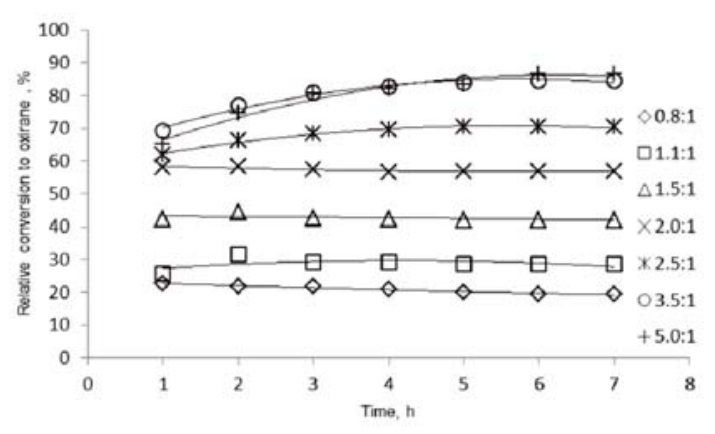

Figure 5. Effect of hydrogen peroxide to ethylenic unsaturation molar ratio $\left(\mathrm{H}_{2} \mathrm{O}_{2} / \mathrm{C}=\mathrm{C}\right)$ on relative conversion to oxirane (RCO). Conditions: temperature $80^{\circ} \mathrm{C}$, formic acid to ethylenic unsaturation molar ratio $\mathrm{HCOOH} / \mathrm{C}=\mathrm{C}=0.8: 1$, amount of catalyst $\left(\mathrm{H}_{2} \mathrm{SO}_{4}\right) /$ $\left(\mathrm{H}_{2} \mathrm{O}_{2}+\mathrm{HCOOH}\right)=1 \mathrm{wt} \%$, stirring speed $700 \mathrm{rpm}$

A similar character of the course of line was observed for the epoxy number (EN) and oxirane oxygen contents 
$\left(\mathrm{EO}_{\mathrm{e}}\right)$. A confirmation of these dependencies was also occurred in the course of changes of the iodine number (IN) versus the time. The maximal values of the process parameters: $\mathrm{EN}, \mathrm{RCO}, \mathrm{EO}_{\mathrm{e}}, \mathrm{C}_{\mathrm{SO}}, \mathrm{S}$ and simultaneously the lowest value of IN were achieved at the molar ratio $\mathrm{H}_{2} \mathrm{O}_{2} / \mathrm{C}=\mathrm{C}=3.5: 1$, after the time $6 \mathrm{~h}$ (Table 2).

A required excess of hydrogen peroxide in relation to ethylenic unsaturation may result from a partial, ineffective decomposition of $\mathrm{H}_{2} \mathrm{O}_{2}$ to water and oxygen. The molar ratio of $\mathrm{H}_{2} \mathrm{O}_{2} / \mathrm{C}=\mathrm{C}=5.0: 1$ is too high because it significantly reduces the selectivity of transformation to the epoxidized oil. This proceed mostly due to the reaction of the oxirane rings with water and formic acid. A similar tendency of the influence of hydrogen peroxide to ethylenic unsaturation molar ratio $\mathrm{H}_{2} \mathrm{O}_{2} / \mathrm{C}=\mathrm{C}$ on the course of jatropha oil epoxidation was found by Goud ${ }^{28}$.

Influence of stirring speed. The effect of this parameter was investigated at stirring speeds: 200, 400, 700, 1000 $1800 \mathrm{rpm}$ and amount of catalyst $1.0 \mathrm{wt} \%$. The most beneficial remaining tested parameters were used and were as follows: temperature $80^{\circ} \mathrm{C}$, the molar ratio of $\mathrm{H}_{2} \mathrm{O}_{2} / \mathrm{C}=\mathrm{C}=3.5: 1, \mathrm{HCOOH} / \mathrm{C}=\mathrm{C}=0.8: 1$, and amount of catalyst $1.0 \mathrm{wt} \%$. Fig. 6 shows diminishing courses of iodine number (IN) function, and increasing oxirane oxygen contents $\left(\mathrm{EO}_{\mathrm{e}}\right)$ for the above mentioned stirring speeds after the time from 1 to $6 \mathrm{~h}$. These values maintain constant values after 6 hours.

Similar systems of lines (not shown in figures) show a growing tendency as a function of the reaction time occurred for the epoxy number (EN) and a relative conversion to oxirane (RCO). In all courses of relationships: IN, EN, RCO, $\mathrm{EO}_{\mathrm{e}}$ vs. time were observed slight differences among their values, after specified reaction time, at speeds above $400 \mathrm{rpm}$. These values revealed that the stirring speed influenced the course of process. Thus, the stirring speed of at least $700 \mathrm{rpm}$ was recognized as satisfactory for the time of process operation from 5 to $7 \mathrm{~h}$. A homogeneous reaction mixture is obtained at this and higher mixing rates. There is no decrease of the reaction rate due to a transport of reagents and there are no local high $\mathrm{H}_{2} \mathrm{O}_{2}$ and peracid concentrations, which could form an explosive mixture.

Comparison of technological parameters and results of epoxidation of sesame oil with performic and peracetic acids. The optimal technological parameters of sesame oil epoxidation are very similar to those obtained during

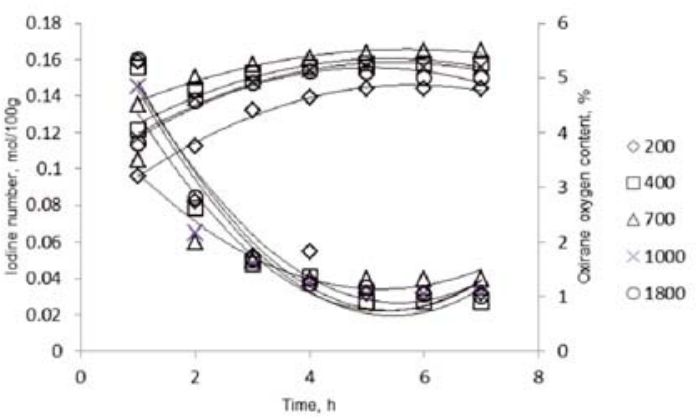

Figure 6. Effect of stirring speed on the iodine number (IN) and oxirane oxygen content (EOe). Conditions: temperature $80^{\circ} \mathrm{C}$, hydrogen peroxide to ethylenic unsaturation molar ratio $\mathrm{H}_{2} \mathrm{O}_{2} / \mathrm{C}=\mathrm{C}=3.5$ :1, formic acid to ethylenic unsaturation molar ratio $\mathrm{HCOOH} /$ $\mathrm{C}=\mathrm{C}=0.8: 1$, amount of catalyst $\left(\mathrm{H}_{2} \mathrm{SO}_{4}\right) /\left(\mathrm{H}_{2} \mathrm{O}_{2}\right.$ $+\mathrm{HCOOH})=1 \mathrm{wt} \%$

the epoxidation with peracetic acid, with slightly different values of the process parameters (results) ${ }^{22}$ - Table 2 . At the identical values of technological parameters: the molar ratio of formic or acetic acid to ethylenic unsaturation $\mathrm{HCOOH}$ or $\left(\mathrm{CH}_{3} \mathrm{COOH}\right) / \mathrm{C}=\mathrm{C}=0.8: 1$, hydrogen peroxide to ethylenic unsaturation $\mathrm{H}_{2} \mathrm{O}_{2} /$ $\mathrm{C}=\mathrm{C}=3.5: 1$ and stirring speed at least $700 \mathrm{rpm}$ in the case of formic acid it is necessary to decrease the temperature to $80^{\circ} \mathrm{C}$ and the catalyst concentration to $\left(\mathrm{H}_{2} \mathrm{SO}_{4}\right) /\left(\mathrm{H}_{2} \mathrm{O}_{2}+\mathrm{HCOOH}\right)=1.0 \mathrm{wt} \%$. Prolongation of the reaction time from $4 \mathrm{~h}$ to $6 \mathrm{~h}$ (performic or peracetic acid) does not cause a decrease of the basic results at the most favorable remaining parameters characterizing the process: $\mathrm{S}, \mathrm{EN}, \mathrm{EO}_{\mathrm{e}}, \mathrm{RCO}$. However, in the presence of performic acid is obtained a slightly lower conversion of oil $\mathrm{C}_{\mathrm{SO}}=90.7 \%$ and higher selectivity $93.2 \%$. This may be due to a higher acidity of formic acid in comparison to the acidity of acetic acid $(\mathrm{pKa}(\mathrm{HCOOH})=3.74$, pKa $\left.\left(\mathrm{CH}_{3} \mathrm{COOH}\right)=4.77\right)$. The use of formic acid produces more proton than acetic acid which catalyzes the perhydrolysis reaction. Hence, a high acidity of formic acid increases the rate of epoxidation. A comparison of the course of changes of the iodine numbers as a function of time, in the presence of both peracids at lower temperatures $\left(30,45,60^{\circ} \mathrm{C}\right)$ and at similar other technological parameters also indicates a higher epoxidation rate in the presence of performic acid. At higher temperatures $\left(75^{\circ} \mathrm{C}\right.$ and $\left.90^{\circ} \mathrm{C}\right)$ the differences in

Table 2. The optimal technological parameters and corresponding to them process parameters (results) of sesame oil epoxidation with performic and peracetic acids

\begin{tabular}{|l|l|c|c|}
\hline Technological parameter & \multicolumn{1}{|c|}{ Performic acid } & Peracetic acid ${ }^{22}$ \\
\hline Temperature & ${ }^{\circ} \mathrm{C}$ & 80 & 90 \\
\hline Carboxylic acid/C=C molar ratio & $\mathrm{mol} / \mathrm{mol}$ & $0.8: 1$ & $0.8: 1$ \\
\hline $\mathrm{H}_{2} \mathrm{O}_{2} / \mathrm{C}=\mathrm{C}$ molar ratio & $\mathrm{mol} / \mathrm{mol}$ & $3.5: 1$ & $3.5: 1$ \\
\hline$\left(\mathrm{H}_{2} \mathrm{SO}_{4}\right) /\left(\mathrm{H}_{2} \mathrm{O}_{2}+\mathrm{HCOOH}\right)$ & $\mathrm{wt} \%$ & 7.0 & 3.0 \\
\hline Stirring speed & $\mathrm{rpm}$ & 4 & 700 \\
\hline Reaction time & $\mathrm{h}$ & & 4 \\
\hline Process parameters (results) & & 0.04 & 0.03 \\
\hline lodine number IN & $\mathrm{mol} / 100 \mathrm{~g}$ oil & 10.2 & 7.6 \\
\hline Epoxy number EN & $\mathrm{g} / 100 \mathrm{~g}$ oil & 0.34 & 0.33 \\
\hline Selectivity S & $\mathrm{mol} / 100 \mathrm{~g}$ oil & 93.2 & 87.6 \\
\hline Conversion $\mathrm{S}$ & $\%$ & 90.7 & 93.0 \\
\hline Relative conversion to oxirane $\mathrm{RCO}$ & $\%$ & 84.6 & 81.5 \\
\hline Oxirane oxygen content EO & $\%$ & 5.5 \\
\hline Glycols concentration & $\%$ & 0.03 & 0.02 \\
\hline
\end{tabular}


the reaction rate in the presence of each of peracids are very small. In both final products of the epoxidation, glycols are present at similar levels of concentration $0.02-0.05 \mathrm{~mol} / 100 \mathrm{~g}$.

A one-time introduction of hydrogen peroxide into the reaction mixture, under the optimal parameters, causes the momentary growth of the reaction temperature by $2-3^{\circ} \mathrm{C}$. There is no difficulty in the removal of the process heat in realized scale of epoxidation. This was caused by a higher rates of epoxidation stage of the double bond by peracid in a comparison with the rate of peracids formation. However, in the case of process development will emerge the necessity of removal of larger amounts of heat in relation to unit of cooling surface. Hence, overheating of the reactor may occur and throwing its content. This is confirmed in the works depicting the best operating conditions ${ }^{31,32}$ presented by the yield, selectivity and in terms of safe conditions. This conditions limit the risk of runway reactions. Conditions for epoxidation of soybean oil in semi-bath reactors are as follows: $\left(\mathrm{HCOOH}+\mathrm{H}_{2} \mathrm{O}_{2}\right)$ volumetric feed rate $0.83-1.66 \cdot 10^{-8}$ $\mathrm{m}^{3} / \mathrm{s}$, temperature $60-80^{\circ} \mathrm{C}$, excess of $\left(\mathrm{HCOOH}+\mathrm{H}_{2} \mathrm{O}_{2}\right)$ stream in relation to soybean oil up to $30 \%$.

\section{CONCLUSIONS}

The studies confirm the possibility of epoxidized sesame oil production in spite of a significant content of linoleic acid (9 cis, 12 cis). The most advantageous technological parameters of epoxidation of sesame oil with performic acid, formed "in situ" in the reaction of formic acid with a $30 \mathrm{wt} \%$ hydrogen peroxide in the presence of sulphuric acid(VI) as a catalyst are as follows: temperature $80^{\circ} \mathrm{C}$, $\mathrm{H}_{2} \mathrm{O}_{2} / \mathrm{C}=\mathrm{C}=3.5: 1, \mathrm{HCOOH} / \mathrm{C}=\mathrm{C}=0.8: 1,\left(\mathrm{H}_{2} \mathrm{SO}_{4}\right) /$ $\left(\mathrm{H}_{2} \mathrm{O}_{2}+\mathrm{HCOOH}\right) 1.0 \mathrm{wt} \%$, stirring speed $700 \mathrm{rpm}$, reaction time $6 \mathrm{~h}$. Under these conditions the epoxidized sesame oil with the epoxy number $\mathrm{EN}=0.34 \mathrm{~mol} / 100 \mathrm{~g}$ oil and the iodine number IN $=0.04 \mathrm{~mol} / 100 \mathrm{~g}$ oil $(10.2$ $\mathrm{g} / 100 \mathrm{~g}$ oil) was obtained. Simultaneously, the oxirane oxygen content was $\mathrm{EO}_{\mathrm{e}}=5.5 \%$ and a relative conversion to oxirane $\mathrm{RCO}=84.6 \%$. The sesame oil conversion at these technological parameters amounted to $90.7 \%$, and the selectivity to epoxidized sesame oil $93.2 \%$. The optimal technological parameters and calculated process parameters (results): IN, EN, $\mathrm{EO}_{\mathrm{e}}, \mathrm{C}_{\mathrm{SO}}, \mathrm{S}, \mathrm{RCO}$ ) of epoxidation with performic and peracetic acid are similar.

\section{ACKNOWLEDGMENT}

This work was funded by Ministry of Science and Higher Education (Poland, No. 517-10-014-4758/17)

\section{LITERATURE CITED}

1. Gan, L.H., Ooi, K.S., Goh, S.H., Gan, L.M. \& Leong, Y.C. (1995). Epoxidized esters of palm olein as plasticizers for poly(vinyl chloride). Europ. Polym. J. 31, 719-724. DOI: 10.1016/0014-3057(95)00031-3.

2. Bunker, S.P. \& Wool, R.P. (2002). Synthesis and characterization of monomers and polymers for adhesives from methyl oleate. J. Polym. Sci. Part A: Polym. Chem. 40, 451-458. DOI: $10.1002 /$ pola.10130.

3. Petrović, Z.S., Zlatanić, A., Lava, C.C. \& SinadovićFišer, S. (2002). Epoxidation of soybean oil in toluene with peroxoacetic and peroxoformic acids - kinetics and side reactions. Eur. J. Lipid Sci. Technol. 104, 293299. DOI: 10.1002/1438-9312(200205)104:5<293::AIDEJLT293>3.0.CO;2-W.

4. Meshram, P.D., Puri, R.G. \& Patil, H.V. (2011). Epoxidation of wild safflower (carthamus oxyacantha) oil with peroxy acid in presence of strongly acidic cation exchange resin IR-122 as catalyst. Int. J. Chem. Tech. Res. 3(3), 1152-1163.

5. Goud, V.V., Patwardhan, A.V., Dinda, S. \& Pradhan, N.C. (2007). Epoxidation of karanja (Pongamia glabra) oil catalyzed by acidic ion exchange resin. Eur. J. Lipid. Sci. Technol. 109, 575-584. DOI: 10.1002/ejlt.200600298.

6. Gurbanov, M.Sh., Mamedov, B.A. (2009). Epoxidation of flax oil with hydrogen peroxide in a conjugate system in the presence of acetic acid and chlorinated cation exchanger KU2x8 as catalyst. Russ. J. Appl. Chem. 82(8), 1483-1487. DOI: 10.1134/S1070427209080308.

7. Poli, E., Clacens, J.M., Barrault, J., Pouilloux, Y. (2009). Solvent-free selective epoxidation of fatty esters over a tungstenbased catalyst. Catal. Today. 140(1-2), 19-22. DOI: 10.1016/j. cattod.2008.07.004.

8. Benaniba, M.T., Belhaneche-Bensemra, N. \& Gelbard, G. (2007). Kinetics of tungsten-catalyzed sunflower oil epoxidation studied by ${ }^{1}$ H NMR. Eur. J. Lipid Sci. Technol. 109(12), 1186-1193. DOI: 10.1002/ejlt.200700114.

9. Rios, L.A., Weckes, P., Schuster, H. \& Hoelderich, W.F. (2005). Mesoporous and amorphous Ti-silicas on the epoxidation of vegetable oils. J. Catal. 232(1), 19-26. DOI: 10.1016/j.jcat.2005.02.011.

10. Ye, X., Jiang, P., Zhang, P., Dong, Y., Jia, Ch., Zhang, X. \& Xu, H. (2010). Novel Ti and mesoporous molecular sieves: synthesis, characterization and catalytic activity in the epoxidation of vegetable oil. Catal. Lett. 137(1-2), 88-93. DOI: 10.1007/s10562-010-0334-z.

11. Gerbase, E., Gregório, J.R., Martinelli, M., Brasil, M.C. \& Mendes, A.N.F. (2002). Epoxidation of soybean oil by the methyltrioxorenium $\mathrm{CH}_{2} \mathrm{Cl}_{2} / \mathrm{H}_{2} \mathrm{O}_{2}$ catalytic biphasic system. J. Am. Oil Chem. Soc. 79(2), 179-181. DOI: 10.1007/s11746002-0455-0.

12. Rüsch gen. Klaas, M. \& Warwel, S. (1999). Complete and partial epoxidation of plant oils by lipase-catalyzed perhydrolysis. Ind. Crop. Prod. 9(2), 125-132. DOI: 10.1016/ S0926-6690(98)00023-5.

13. Milchert, E., Malarczyk, K. \& Kłos, M. (2015). Technological Aspects of Chemoenzymatic Epoxidation of Fatty Acids, Fatty Acid Esters and Vegetable Oils: A Review. Molecules 20(12), 21481-21493. DOI: 10.3390/molecules201219778.

14. Metzger, J.O. \& Bornscheuer, U.T. (2006). Lipids as renewable resources: Current state of chemical and biotechnological conversion and divesification. Appl. Microbiol. Biotechnol. 71(1), 13-22. DOI: 10.1007/s00253-006-0335-4.

15. Tan, S.G. \& Chow, W.S. (2010). Biobased Epoxidized Vegetable Oils and Its Greener Epoxy Blends: A Review. Polym. Plast. Technol. Eng. 49(15), 1581-1590. DOI: 10.1080/03602559.2010.512338.

16. Patil, H., Waghmare, J. (2013). Catalyst for epoxidation of oils: a review. Discovery 3(7), 10-14.

17. Bang Hyo-Jeong, Kim Cheong-Tae, Byung Hee Kim (2014). Liquid and gas chromatographic analyses of triacylglycerols for Asian sesame oil traceability. Eur. J. Lipid Sci. Technol. 116(10), 1354-1362. DOI: 10.1002/ejlt.201400089.

18. Saydut, A., Duz, M.Z., Kaya, C., Kafadar, C. \& Hamamci, A.B. (2008). Transesterified sesame (Sesamum indicum L.) seed oil as a biodiesel fuel. Bioresource Technol. 99(14), 6656-6660. DOI: 10.1016/j.biortech.2007.11.063.

19. Mohamed, H.M.A. \& Awatif, I.I. (1998). The use of sesame oil unsaponifiable matter as a natural antioxidant. Food Chem. 62 (3), 269-276. DOI: 10.1016/S0308-8146(97)00193-3.

20. Mordret, F. (1968). Detection of sesame oil. J. Crops Grass 6, 389-397. 
21. Filippis, P.D., Scarsella, M. \& Verdone, N. (2009). Peroxyformic acid formation: a kinetic study. Ind. Eng. Chem. Res. 48(3), 1372-1375. DOI: 10.1021/ie801163j.

22. Musik, M. \& Michert, E. (2017). Selectice epoxidation of sesame oil with peracetic acid. Mol. Catalysis 433, 170-174. DOI: 10.1016/j.mcat.2017.02.012.

23. International standard EN ISO 5508, Analysis by gas chromatography of methyl esters of fatty acids.

24. International standard EN ISO 3961, Animal and vegetable fats and oils. Determination of iodine value.

25. International standard EN ISO 3001, Plastics, epoxy compounds. Determination of epoxy equivalent.

26. Gupta, S.S., Guchhait, A., Sarkar, S. \& Ghosh, M. (2016). Comparative evaluation of the physico-chemical properties of chemically and enzymatically epoxidised soybean oil. Int. Res. J. Chem. 1(2), 17-24.

27. Mungroo, R., Pradhan, N.C., Goud, V.V. \& Dalai, A.K. (2008). Epoxidation of canola oil with hydrogen peroxide catalyzed by acidic ion exchange resin. J. Am. Oil Chem. Soc. 85(9), 887-896. DOI: 10.1007/s11746-008-1277-z.

28. Goud, V.V., Dinda, S., Patwardhan, A.V. \& Pradhan, N.C. (2010). Epoxidation of jatropha (Jatropha curcas) oil by peroxyacids. Asia-Pacyfic J. Chem. Eng. 5(2), 346-354. DOI: 10.1002/apj.285.

29. Stenmark, G.A. (1958). Determination of alpha-glycol content of epoxy resins. Anal. Chem. 30(3), 381-383. DOI: 10.1021/ac60135a020.

30. Goud, V.V., Patwardhan, A.V. \& Pradhan, N.C. (2006). Studies on the epoxidation of mahua oil (Madhumica indica) by hydrogen peroxide. Bioresource Technol. 97(12), 1365-1371. DOI: 10.1016/j.biortech.2005.07.004.

31. Moreno, V.C., Russo, V., Tesser, R. \& Serio, M.D., Salzano E. (2017). Thermal risk in semi-batch reactors: the epoxidation of soybean oil. Process Saf. Environ. Prot.109, 529-537. DOI: 10.1016/j.psep.2017.05.001.

32. Leveneur, S. (2017). Thermal safety assessment through the concept of structure-reactivity: application to vegetable oil valorization. Org. Process Res. Dev. 21(4), 543-550. DOI: 10.1021/acs.oprd.6b00405. 